\title{
Station-scale bias correction and uncertainty analysis for the estimation of irrigation water requirements in the Swiss Rhone catchment under climate change
}

\author{
Pascalle C. Smith • Georg Heinrich • Martin Suklitsch • \\ Andreas Gobiet • Markus Stoffel • Jürg Fuhrer
}

Received: 26 September 2013 / Accepted: 18 September 2014 / Published online: 6 November 2014

(C) Springer Science+Business Media Dordrecht 2014

\begin{abstract}
Irrigation water requirements (IWR) are expected to be influenced by changes in the climate variables driving water availability in the soil-plant system. Most of the agricultural surface areas of the heterogeneous Swiss Rhone catchment are already exposed to drought. Aiming at investigating future pressures on the water resources to fill the growing gap between rain-fed and optimum water supply for cultivation, we downscaled and bias corrected 16 regional climate scenarios from the ENSEMBLES dataset for the period 1951-2050 using a Quantile Mapping methodology calibrated with daily observations from 5 contrasting weather stations. The data reveal an increased evaporative demand over the growing season for almost all stations and scenarios (2021-2049 vs. 1981-2009). The picture is less clear for precipitation, with a projected decrease or increase depending on the scenario, station and month. The main results indicate that bias correction of climate scenarios not only reduces the remaining error between baseline and observations but also enhances the change signal in seasonal IWR estimates. This is due to a higher and more realistic sensitivity of IWR to the atmospheric water budget, the slope of this relationship being steeper in the observations than in the uncorrected data. The seasonal cycle of the IWR change signal shows different sensitivities and climate drivers across crops (grassland and maize) and stations, but a consistent trend towards an increase despite uncertainty. This increased water demand will have to be reconciled with possibly decreased or shifted future water availability from glacier and snow melt.
\end{abstract}

P. C. Smith $(\bowtie) \cdot$ J. Fuhrer

Agroscope, Air pollution/Climate Group, Reckenholzstrasse 191, 8046 Zürich, Switzerland

e-mail: pascalle.smith@laposte.net

P. C. Smith • M. Stoffel

Institute for Environmental Sciences, University of Geneva, 7 route de Drize, 1227 Carouge, Switzerland

P. C. Smith • G. Heinrich • M. Suklitsch • A. Gobiet

Wegener Center for Climate and Global Change, University of Graz, Brandhofgasse 5, 8010 Graz, Austria

M. Suklitsch

Central Institute for Meteorology and Geodynamics, Hohe Warte 38, 1190 Vienna, Austria 


\section{Introduction}

The European Alps are considered the 'water tower of Europe' because they act as the most important freshwater supply of continental Europe (Viviroli and Weingartner 2008, Beniston et al. 2011). At the same time, the Alpine region is an area extremely sensitive and vulnerable to the influences of global changes, including global warming and changing human interventions (Steininger and Weck-Hannemann 2002). In order to maintain the structure and multifunctionality of alpine regions, it is essential to understand the sensitivities to projected future changes, in different sectors involved in the utilization of alpine resources such as land and water. There are a number of potential impacts on the agricultural sector in the course of future climate change. For instance, Gobiet et al. (2013) expect about $0.25{ }^{\circ} \mathrm{C}$ warming per decade until the mid of the $21^{\text {st }}$ century and accelerated $0.36{ }^{\circ} \mathrm{C}$ warming per decade in the second half of the century under the A1B greenhouse gas emission scenario (Nakicenovic et al. 2000). They further expect that warming will probably be associated with changes in the seasonality of precipitation, global radiation, and relative humidity, and more intense precipitation extremes and flooding potential in the colder part of the year. The conditions of currently record breaking warm or hot winter or summer seasons, respectively, may become normal at the end of the $21^{\text {st }}$ century, and there is indication for droughts to become more severe in the future (IPCC, 2012).

In the Swiss Rhone catchment, irrigation is an important agricultural issue because of the rain-shadow effect during the summer. Over $400 \mathrm{~mm}$ water are currently required per year for grassland irrigation in the driest area of the catchment. As summarized in Fuhrer et al. (2013), irrigation has been the traditional response to the dry conditions, with the largest fraction allocated to grasslands used for livestock, followed by orchards and vineyards. Increasing use of irrigation to maintain crop, pasture and livestock productivity could generate more competition between different users of possibly declining water resources during the summer months because of climate change. In order to design appropriate adaptation measures to cope with these conflicting situations, improved estimates of changes in irrigation water requirements (IWR) at the catchment and sub-catchment scales are required.

The present study is part of a project that aims at quantifying future potential IWR for the Swiss Rhone catchment, which are expected to be influenced by changes in the climate variables driving water availability in the soil-plant system (Fuhrer et al. 2013). The atmospheric input variables for the soil water balance calculations were extracted from state-of-theart regional climate model (RCM) simulations from the EU-FP6 project ENSEMBLES. The associated uncertainties are taken into account as far as possible by analyzing an appropriate ensemble of RCM projections until the mid of the $21^{\text {st }}$ century. Although the use of RCMs is favorable compared to global climate models (GCMs), as the former are able to resolve physical processes at finer spatial and temporal scales, they still do not fully capture the orography and associated effects on meteorological elements in narrow alpine valleys and feature substantial errors in reproducing present-day climate conditions (e.g., Frei et al. 2003; Hagemann et al. 2004; Suklitsch et al. 2008, 2011). Since errors in climate simulations substantially affect the assessment of climate change impacts (e.g., Fowler et al. 2007), it is a crucial step to further adjust the output of RCMs to local climate conditions at specific meteorological stations especially in the Alpine region with its large topographic variability. In this study, this is achieved by applying a distribution based empirical-statistical error correction and downscaling approach, thus combining both the advantages of dynamical and empiricalstatistical downscaling methods.

Using such adjusted RCM outputs as inputs for an algorithm computing crop and soil specific IWR at the local scale with a daily time step, this study aims at investigating the effect 
of statistical post-processing of RCM output on the error in simulating present-day IWR and further analyzing its impact on the plausibility of the projected IWR changes.

\section{Data and methods}

First we present the climate data as well as the scenario downscaling methodology aiming at minimizing the remaining error between baseline and observations for a reference period up to present-day conditions. Then we describe the selected stations and chosen dataset nomenclature. Finally we give a short insight into the impact modeling for which the corrected climate scenarios serve as input and introduce the uncertainty analysis of irrigation projections.

\subsection{Climate scenarios and required variables}

The study is based on daily outputs from 16 RCMs using boundary conditions from 8 GCMs made available by the EU-FP6 project ENSEMBLES (http://www.ensembles-eu. org) on a $25 \times 25 \mathrm{~km}$ grid. The ensemble mainly addresses uncertainty in boundary conditions (i.e. choice of the driving GCM) and RCM formulation (Boberg et al. 2010). The ENSEMBLES multi-model dataset can be regarded as the currently most comprehensive information source for the evolution of climate over Europe in the $21^{\text {st }}$ century. The robustness of the ensemble has been demonstrated by Heinrich et al. (2013), who showed that it covers the entire range of driving GCM uncertainty known from the much larger CMIP3 ensemble (Meehl et al. 2007). All simulations are based on the IPCC A1B greenhouse gas emission scenario (Nakicenovic et al. 2000). Compared with other scenarios, the A1B scenario only leads to marginally different climate projections over Europe during the first half of the $21^{\text {st }}$ century (Prein et al. 2011); it can therefore be regarded as representative of the climate that is expected until 2050, at least for the three widely used emission scenarios from the IPCC AR4 report (A1B, B1, A2) (IPCC, 2007). In contrast, for the late-century (not analyzed here), the other two main emission scenarios from the IPCC AR4 report, namely B1 and A2 (IPCC, 2007), lead to significantly lower (B1) or higher temperatures (A2).

From the full set of 22 available simulations in ENSEMBLES, we extracted 16 scenarios (see legend of Fig. 1b) as a homogeneous set in terms of starting date and available variables of time series from 1950 to 2050 . Note that for simplicity, in the following we refer to "scenarios" as the realizations of the emission scenario A1B calculated by the 16 RCMs. Daily cumulated precipitation $(\mathrm{P})$, average 2-m air temperature, global radiation, relative humidity, wind and atmospheric pressure at sea level were needed for the computation of the reference evapotranspiration $\left(\mathrm{ET}_{0}\right)$.

Recently, a new set of regional climate simulations became available from the EURO-CORDEX initiative (Jacob et al. 2013). These simulations for Europe downscale the new CMIP5 global climate projections (Taylor et al. 2012) and the new representative concentration pathways (RCPs) (van Vuuren et al. 2011). At the time of the analysis conducted in this paper, the EURO-CORDEX simulations were not yet available. However, a first analysis of the EURO-CORDEX results given in Jacob et al. (2013) suggests that the large-scale patterns of changes in the EURO-CORDEX simulations are similar to those of ENSEMBLES. Therefore we expect that our conclusions would qualitatively also hold if the study were repeated based on the EURO-CORDEX climate simulations. 

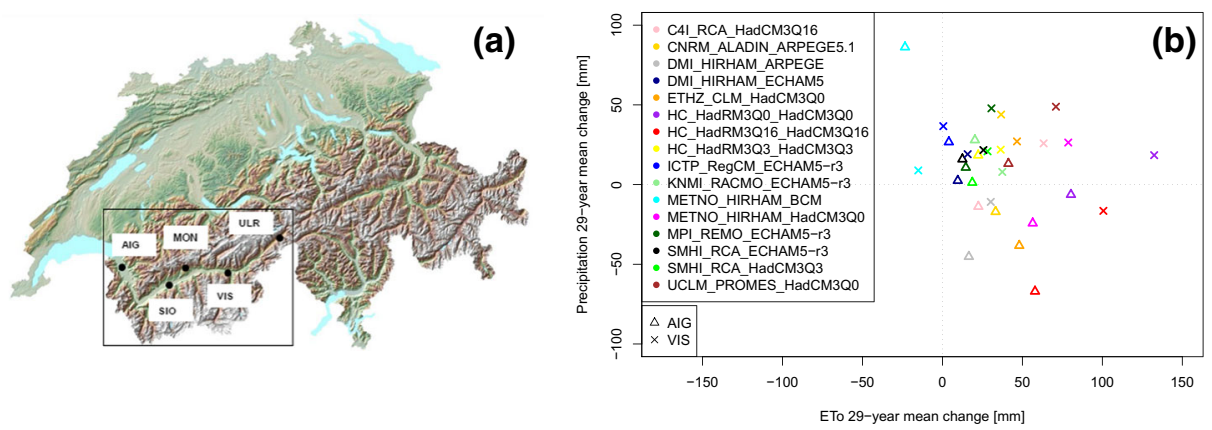

Fig. 1 a Location of the 5 selected MeteoSwiss weather stations within Canton Valais and Switzerland's topography. b Scatter plot: 29-year mean climate change signal (represented by P \& ET $_{0}$ ) between 1981-2009 and 2021-2049 (March to October sums [mm]), spread across stations (symbols), and scenarios (colors)

\subsection{Bias correction and downscaling of regional climate scenarios to the station scale}

As RCMs are known to suffer from systematic errors (e.g., Frei et al. 2003; Hagemann et al. 2004; Suklitsch et al. 2008, 2011), an empirical-statistical bias correction and downscaling approach via Quantile Mapping (QM; e.g., Dobler and Ahrens 2008; Piani et al. 2010; Yang et al. 2010; Themessl et al. 2011a, b; Dosio et al. 2012) was applied to adjust and refine RCM results towards the local-scale observations, using the daily observational data from 5 MeteoSwiss weather stations (Fig. 1a). The bias correction for this study was performed within the framework of the EU-FP7 project ACQWA (http://www.acqwa.ch, Beniston et al. 2011) and is a purely empirical implementation of QM on daily basis, identical to the method described by Themessl et al. (2011a, b) for temperature and precipitation, and by Wilcke et al. (2013) for additional meteorological variables. It was already applied in other climate change impact studies (Finger et al. 2012; Heinrich and Gobiet 2012, Fuhrer et al. 2013). QM adapts simulated time series by adjusting the empirical cumulative frequency distributions of the selected daily climate variables to the observed frequency distribution of the 29-year calibration period 1981-2009. This means that the bias-corrected model data have the same distributional properties as the observed data over the calibration period, but the chronological sequence of weather patterns originates from the RCM. The effective resolution of the RCMs (e.g., Denis et al. 2002) was taken into account by considering the 4 grid cells nearest to the location of each station. As bias correction was applied to the entire 100-year period 19512050, we extrapolated the correction term of the most extreme value from the calibration period, as applied in Themessl et al. (2011a, b), to allow values beyond the calibration range. Compared to other bias correction methods like the delta change or scaling approaches (e.g., Deque 2007), QM has the advantage to be sensitive to some degree to different meteorological situations by adjusting the entire distribution, and not only the mean of a variable. Implicitly, changes in the temporal variability and extremes simulated by the climate model remain in the date also after bias correction, although there are only very few evaluation studies available regarding extremes (e.g., very briefly in Themessl et al. 2011a, b). In addition, some restrictions apply regarding very small scale spatial variability, if QM is used not only as bias correction method, but also as downscaling method (Maraun 2013). However, Themessl et al. (2011a, b) compared several bias correction methods and identified QM as being superior, and Gudmundsson et al. 2012 showed that the parameter-free implementation of QM used here outperforms other implementations. 


\subsection{Station selection, observations, and dataset nomenclature}

Observed data for 1981-2009 are referred to in the following as "Obs", scenario data extracted from the bias-corrected time series for this same period as "Base", and for the 29-year period 2021-2049 as "Future". With "Error" we mean the difference "Base - Obs" and with "Change" the difference "Future - Base". The same nomenclature is used for climate impact simulation results driven with these observed and scenario data. Scenario data extracted from the original ENSEMBLES time series before bias-correction are referred to as "uncorrBase", "uncorrFuture", "uncorrError" and "uncorrChange". Inter-annual variability is not analyzed here, i.e. we refer systematically to the 29 -year mean over the Base and Future selected periods.

Five weather stations from MeteoSwiss (Aigle/AIG, Sion/SIO, Visp/VIS, Montana/MON and Ulrichen/ULR) were selected as in Smith et al. (2012) covering an elevation and West-East gradient representative for growing conditions of the main crops in the Swiss Rhone catchment (Fig. 1a). The AIG station is the lowest and a good representative for a relatively humid climate benefiting from twice as much precipitation over March to October as the VIS station, which is representative for the driest climate in the catchment (mean Obs: $731 \mathrm{~mm}$ vs. $382 \mathrm{~mm}$, Table 1).

\subsection{Computation of evapo-transpiration and irrigation water requirement}

Daily $\mathrm{ET}_{0}$ was computed for each station as in Smith et al. (2012), following recommendations by Allen et al. (1998), and inserted into the vertical soil water balance Eq. 1. The difference P$\mathrm{ET}_{0}$ is known as the "atmospheric water budget". It is a typical index of water deficit or excess from an atmospheric point of view without consideration of soil and plant properties. The ground layer modulates water supply from the soil (i.e. large/small water holding capacity) and demand by the plant (i.e. more/less than the reference vegetation), inducing variable additional water needs to fill the supply-demand gap.

The vertical soil water balance equation can be written as:

$$
\frac{d}{d t}\left(D_{r}\right)=-(P-R O-D P)-I W R+K_{s} \cdot K_{c} \cdot E T_{0}
$$

where $D_{r}$ is the actual soil water depletion, $R O$ the surface runoff, and $D P$ the deep percolation. $K_{s}$ is called the soil water stress factor and $K_{c}$ the crop coefficient. All precipitation in excess of the infiltration capacity (which is the difference between soil porosity and actual

Table 1 Synthesis: The first line gives in [mm] the past observed reference 1981-2009 climate $\left(\mathrm{P} \& \mathrm{ET}_{0}\right)$ and IWR (March-October sums for grassland, April-September for Maize), the second line the 29-year mean Change average across scenarios ( \pm standard deviation across scenarios) expressed in [mm]

\begin{tabular}{|c|c|c|c|c|c|c|c|}
\hline & & $\begin{array}{l}\text { AIG } \\
\text { maize }\end{array}$ & $\begin{array}{l}\text { AIG } \\
\text { grassland }\end{array}$ & $\begin{array}{l}\text { SIO } \\
\text { grassland }\end{array}$ & $\begin{array}{l}\text { VIS } \\
\text { grassland }\end{array}$ & $\begin{array}{l}\text { MON } \\
\text { grassland }\end{array}$ & $\begin{array}{l}\text { ULR } \\
\text { grassland }\end{array}$ \\
\hline $\mathrm{P}$ & Obs $[\mathrm{mm}]$ Change $[\mathrm{mm}]$ & $\begin{array}{l}574 \\
-8( \pm 40)\end{array}$ & $\begin{array}{l}731 \\
-1( \pm 36)\end{array}$ & $\begin{array}{l}392 \\
12( \pm 17)\end{array}$ & $\begin{array}{l}382 \\
22( \pm 18)\end{array}$ & $\begin{array}{l}595 \\
11( \pm 24)\end{array}$ & $\begin{array}{l}789 \\
24( \pm 40)\end{array}$ \\
\hline ETo & Obs $[\mathrm{mm}]$ Change $[\mathrm{mm}]$ & $\begin{array}{l}532 \\
24( \pm 23)\end{array}$ & $\begin{array}{l}619 \\
27( \pm 25)\end{array}$ & $\begin{array}{l}770 \\
39( \pm 32)\end{array}$ & $\begin{array}{l}813 \\
45( \pm 37)\end{array}$ & $\begin{array}{l}656 \\
40( \pm 32)\end{array}$ & $\begin{array}{l}574 \\
35( \pm 26)\end{array}$ \\
\hline Irrigation & Obs [mm] Change $[\mathrm{mm}]$ & $\begin{array}{l}129 \\
28( \pm 28)\end{array}$ & $\begin{array}{l}152 \\
30( \pm 31)\end{array}$ & $\begin{array}{l}385 \\
43( \pm 39)\end{array}$ & $\begin{array}{l}441 \\
45( \pm 39)\end{array}$ & $\begin{array}{l}202 \\
41( \pm 30)\end{array}$ & $\begin{array}{l}137 \\
32( \pm 28)\end{array}$ \\
\hline
\end{tabular}


water content) is removed as surface runoff and all water content in excess of field capacity is removed as deep percolation.

IWR were simulated for each station as the amount of water necessary each day (considering $100 \%$ irrigation efficiency, i.e. no losses through the application method) to maintain root-zone moisture above a pre-defined threshold. In other words, irrigation is triggered whenever $D_{r}>D_{r, \text { trig }}$ to counteract the depletion and to bring back $K_{s}$ to 1 , that is, no stress, implying no effect on evapotranspiration. This trigger threshold depends on soil type and crop sensitivity to drought, and was chosen to correspond to a soil moisture allowing $80 \%$ of maximum crop-specific evaporative demand $\left(K_{s}=0.8\right)$. The water balance of the root zone is solved for a single soil layer of constant thickness across time. $K_{c}$ is the ratio of maximum crop-specific evaporative demand to $\mathrm{ET}_{0}$ and varies along the growing season according to a dynamically simulated phenology. For a given variety of maize, the warmer the climate, the shorter the growing season until harvest. For grassland (perennial crop), the warmer the climate, the longer the growing season and, consequently, the larger the number of cuts or possible grazing events per growing season. Further details and literature sources about $\mathrm{ET}_{0}$ and IWR computation are available in Smith et al. (2012) in section 3.3 (dealing with daily point scale modeling) and references can also be found in section 5 for the evaluation of seasonally and spatially aggregated values over the Swiss Rhone catchment.

To analyze the impact of climate change on IWR, the amount of missing water under rainfed growing conditions was estimated on a daily basis for maize at AIG and for grassland at all 5 stations (Fig. 1a). Simulations were driven by the 29 -year observed and the 16 corrected and uncorrected 100-year scenario time series described in the previous section. A range of 10 soil water holding capacities was tested, but all examples below apply to a soil with $32.2 \mathrm{~mm}$, representing an average soil typical for the Swiss Rhone catchment (see Smith et al. 2012, section 2).

\section{Results and discussion}

The main results described and discussed in the following 3 sections indicate that bias correction not only improves the climate and impact model output in terms of the Error between the Base and Obs but also affects the projected Change in seasonal irrigation estimates. This is a novelty, as, to our knowledge, no other study has investigated this effect specifically. The (corrected) change signal shows across all crops and stations a clear trend towards an increase despite seasonal variations and the uncertainty due to the scenario spread.

\subsection{Climate change signal spread}

For station AIG, about half of the scenarios project a 29 -year mean increase (up to $+86 \mathrm{~mm}$ ) in seasonal P (Fig. 1b), the other half a decrease (down to $-67 \mathrm{~mm}$ ). This wide spread nearly equally distributed around a Change in $\mathrm{P}$ by $0 \mathrm{~mm}$ thus indicates that although the projected effect could be large, its sign is very uncertain at the seasonal level. For VIS, only 2 scenarios project a decrease in $\mathrm{P}$ (down to $-16 \mathrm{~mm}$ ) whereas all others project an increase (up to + $49 \mathrm{~mm}$ ), the extreme values not being systematically generated by the same scenarios for both stations. The spread and related uncertainty around the amount of P Change is twice as large for AIG than for VIS.

The picture is different when looking at the mean Change in $\mathrm{ET}_{0}$ (Fig. 1b): an increase is projected for both stations by all but one scenario $(-28$ to $+132 \mathrm{~mm})$. Its amount and spread are larger for VIS than for AIG, VIS already exhibiting a higher evaporative demand over March 
to October (mean Obs: $813 \mathrm{~mm}$ vs. $619 \mathrm{~mm}$, Table 1). The overall projected $\mathrm{ET}_{0}$ increase due to increased air temperature and radiation and reduced air humidity is consistent with results obtained by Calanca et al. (2006), who recommended including the latter variables in regional climate scenarios for impact studies. The maximum increase in $\mathrm{ET}_{0}(+132 \mathrm{~mm})$ corresponds to an increase in seasonally averaged $2-\mathrm{m}$ air temperature of $+1.6^{\circ} \mathrm{C}$, a global radiation increase of $+0.26 \mathrm{MJ} / \mathrm{m}^{2} /$ day, and a decrease in relative humidity of $-6.8 \%$, and the maximum decrease in $\mathrm{ET}_{0}(-28 \mathrm{~mm})$ corresponds to $+0.2^{\circ} \mathrm{C},-0.60 \mathrm{MJ} / \mathrm{m}^{2} /$ day and $+1.1 \%$, respectively.

The maximum decrease in $\mathrm{ET}_{0}$ (Fig. 1b) results from the same scenario as the maximum increase in $\mathrm{P}(+86 \mathrm{~mm})$ and for the same station, whereas the maximum $\mathrm{ET}_{0}$ increase and maximum $\mathrm{P}$ decrease $(-67 \mathrm{~mm})$ result from different scenarios and stations. Behind the + $58 \mathrm{~mm} \mathrm{ET}_{0}$ increase of the point exhibiting the maximum $\mathrm{P}$ decrease in the triangle-like cloud, changes are $+1.8{ }^{\circ} \mathrm{C},+0.36 \mathrm{MJ} / \mathrm{m}^{2} /$ day and $-1.9 \%$. By construction, $\mathrm{ET}_{0}$ increases with increasing radiation and temperature and decreasing humidity, but the last numbers show that the final pattern integrating all interacting variables, scenarios and stations is complex.

\subsection{Bias correction effect on error and change in atmospheric water budget and IWR}

First of all it was expected that Error, though very small in the individual climate variables after bias correction (e.g., Themessl et al. 2011a, b; Wilcke et al. 2013), propagates in the model chain from the input to the impact model output, IWR. The initial discrepancies between uncorrBase and Obs datasets come from the global and regional climate modeling upstream of the present study. Bias correction then reduces them, but water balance and evapo-transpiration modeling combines them in a nonlinear way into a relative larger error between simulated IWR driven by Base climate and IWR driven by Obs climate. On average over the 29-year Base and Obs period, results reveal an underestimation of IWR over March to October by about $20 \mathrm{~mm}$ for grassland at VIS and overestimation by $20 \mathrm{~mm}$ at AIG (Fig. 2b \& d, note that boxplots illustrate the variability across scenarios, and not across years). However this Error is much smaller (i.e. factor 20 at VIS to -5 at AIG) compared with the original underestimation of -400 and $-100 \mathrm{~mm}$, respectively, obtained in simulations of IWR using the uncorrected climate scenarios. Instead of compensating for each other, the large overestimation of $\mathrm{P}$ and underestimation of $\mathrm{ET}_{0}$ add up to an uncorrError in $\mathrm{P}_{-\mathrm{ET}_{0}}$ of 1,400 $\mathrm{mm}$ at VIS and $800 \mathrm{~mm}$ at AIG (Fig. 2a \& c). With bias correction, this very large overestimation of the atmospheric water budget is reduced to $25 \mathrm{~mm}$ at VIS and $0 \mathrm{~mm}$ at AIG. However, a small Error remains after bias correction, which can be related at least partly to the fact that we did not explicitly correct for autocorrelation (sequence of weather events) and trends in the daily time series. These results demonstrate that even if the meteorological variables are corrected separately and regardless of inter-variable relations, they can successfully be used as joint inputs for an impact model. More generally, this confirms results from Wilcke et al. (2013), who showed the correlation between different meteorological variables is not significantly modified by QM.

The change signal for seasonal $\mathrm{P}_{-} \mathrm{ET}_{0}$, whether uncorrected or corrected, exhibits a decrease for both stations (Fig. 2a-d), thus reflecting an increased atmospheric water deficit, and associated increased IWR (on average over 29 years from the Base to Future period). Across all scenarios, average IWR Change is positive and even larger than (for VIS), or nearly equal to (for AIG), the standard deviation that represents an inter-scenario variability of 86 and $102 \%$ (39/45 resp. 31/30, Table 1). The increase in atmospheric water deficit is mostly driven by the increase in $\mathrm{ET}_{0}$, which is on average across scenarios larger than the increase in $\mathrm{P}$ (Table 1). In the case of AIG, the decrease in P contributes to the larger deficit (Table 1). While the amplitude of the Change in $\mathrm{P}_{-} \mathrm{ET}_{0}$ is reduced by a factor 2 with bias correction (Fig. $2 \mathrm{a} \&$ 
VIS

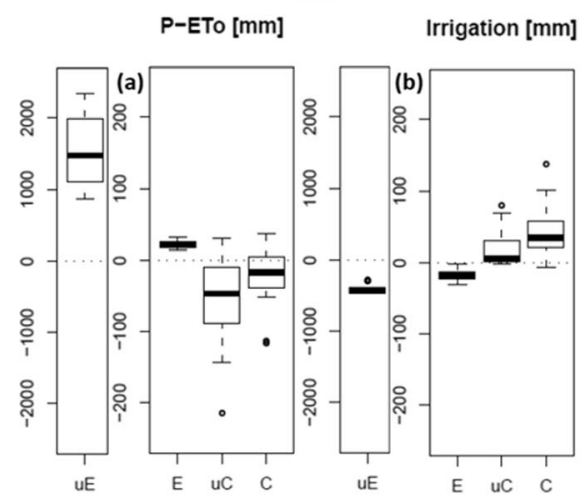

AIG

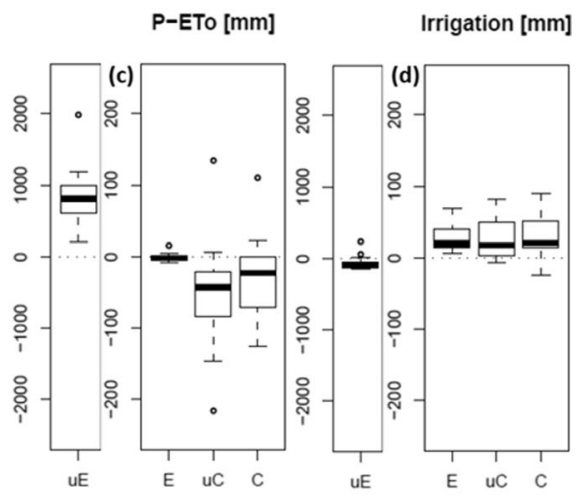

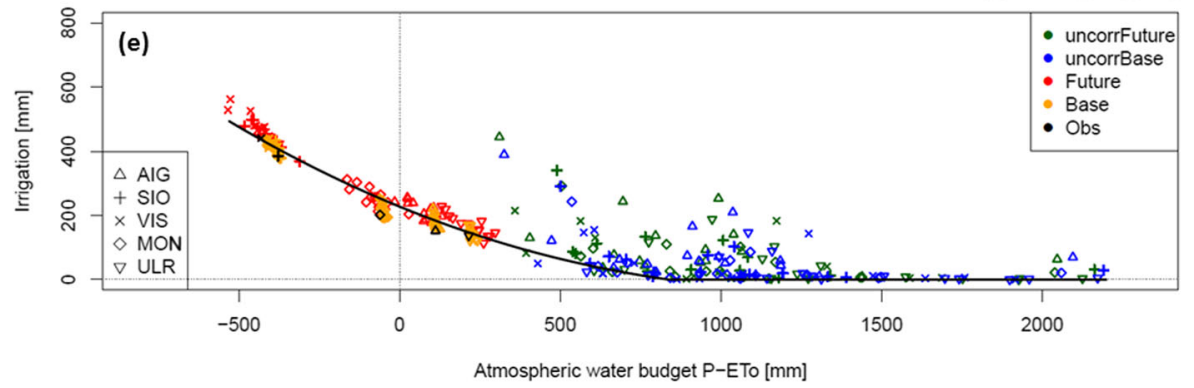

Fig. 2 Box plots: median and spread across scenarios $(5,25,75 \& 95 \%$ quantiles) of uncorrected \& corrected 29-year mean Error \& Change (uE, E, uC \& C) in atmospheric water budget $\left(\mathrm{P}-E T_{0}\right)$ a \& $\mathbf{c}$ and grassland IWR (March to October sums [mm]) $\mathbf{b} \& \mathbf{d}$ for station VIS $\mathbf{a} \& \mathbf{b}$ and AIG $\mathbf{c} \& \mathbf{d}$. Beware of the factor 10 in the Y-axis

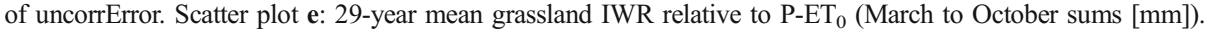
Robust pattern across stations (symbols) and uncorrected, corrected, Obs, Base and Future datasets (colors, all scenarios included, that is: 16 points per color \& symbol). The fit curve uses the "loess" smoothing function applied to the Obs and corrected Base \& Future datasets

c), the amplitude of the Change in IWR increases at VIS from 10 to $45 \mathrm{~mm}$ and from 25 to $30 \mathrm{~mm}$ at AIG (Fig. $2 \mathrm{~b} \& \mathrm{~d}$, Table 1). This result indicates that bias correction leads to a higher sensitivity of IWR to atmospheric water budget, especially at the warmest and driest station VIS.

In the corrected data the average amplitude of grassland IWR Change represents $10 \%$ of the seasonal Obs mean at the dry station VIS, and $20 \%$ at the more humid AIG (Table 1). The coefficient of variation (CV, not shown) across the observed years 1981-2009 (including the 2003 heatwave) is $14 \%$ around the IWR Obs mean of $441 \mathrm{~mm}$ at VIS and $26 \%$ around the mean of $152 \mathrm{~mm}$ at AIG (Table 1). At both stations, this variability across years is larger than that across scenarios (uncertainty range). The CV of the 29-year mean IWR across scenarios in the comparable "absolute" time series Base and Future is 2 and $9 \%$ for VIS and 11 and $15 \%$ for AIG, respectively.

Despite spatio-temporal climate variability, i.e. differences between stations and between years (individual years were simulated but not shown since the focus here was on 29-year mean values and dataset properties affected by bias correction), changes from past to future, scenario ensemble uncertainty and errors between observations and baselines, all data can be fitted by a robust simple relationship linking IWR to P-ET (Fig. 2e). This is particularly the case for the data generated from bias corrected inputs, i.e. the drier the station in terms of 
atmospheric water budget, the larger the amount of irrigation water required. For a given station, if climate change induces a larger atmospheric water deficit as suggested by nearly all scenarios, more irrigation water will be required. This increasing trend was also found for other selected catchments in the country (Fuhrer 2012). The climate change impact appears to be about as large as when moving on the smoothing line in Fig. 2e from one station to the next drier one.

The uncorrected data is more scattered due to large differences between scenarios in the skill of simulating present-day climate conditions. Moreover, no effect due to the location of the stations is identifiable, which can be explained by the relatively coarse (effective) RCM resolution. However, ignoring the scatter, these uncorrected data show many points on the smoothing line expanded from the Obs and corrected Base and Future data, with $0 \mathrm{~mm}$ IWR, independently of atmospheric water budget. This is understandable as no irrigation water is required if $\mathrm{P}$ largely exceeds the evaporative demand $\mathrm{ET}_{0}$ (e.g. 1,000 mm, Fig. 2e). Departures from the robust relationship arise from unrealistic precipitation regimes in a few scenarios. Indeed, for a given soil, the precipitation regime can have a strong influence on additional water needs. For instance, heavy rainfall events saturate the soil more quickly than the evapotranspiration by plants depletes soil water and, consequently, excess water is lost as runoff. This explains why some points indicate a non-zero IWR despite apparent water availability from the atmospheric point of view. Outliers in Fig. 2e belong to scenarios concerned with a flatter distribution of daily precipitation events (not shown) thus implying more extremes.

Overall, Fig. 2e explains the results shown in Fig. 2a-d. Bias correction affects more strongly the data for VIS, as it is the driest of the 5 selected stations and the climatically most distant from the simulated humid conditions in the grid cell extracted from the original ENSEMBLES database. The bias in IWR was larger than the climatic difference between VIS and ULR, the most humid station, and as large as the IWR at VIS according to observations (441 mm, Table 1). Thus, bias correction of daily climate inputs enables switching from climate change insensitive non-irrigation demanding conditions to the more realistic drought and climate change sensitive conditions at the base of the Rhone Valley. This suggests that bias correction improves the plausibility of simulated climate change impacts on daily and, hence, seasonally integrated IWR. This is important with respect to decisions taken in terms of adaptation in agriculture to future climatic conditions, however, without providing a satisfactory physical justification (Ehret et al. 2012). It should also be noted that by applying bias corrections derived from present day to scenario simulations, an assumption is made on the stationarity of the bias, which may lead to unwanted results at longer timescales, as discussed by Haerter et al. (2011).

The existence of a robust and simple relationship between seasonal IWR and P-ET (Fig. 2e) remains valid across crops and soil water holding capacity levels, although only one of the investigated cases is illustrated here. Inter-annual variability around the 29-year mean also goes in the same direction (not shown) and was used together with spatial variability in Smith et al. (2012, section 3.4) for calibrating the coefficients of a single statistical model accounting for crop and soil specificities. The latter can be used to extrapolate seasonal IWR in time and space (Smith et al. 2012, section 4). The results reported here show that data from different scenarios, whether bias corrected or not, and periods (Base/Future) also fit into the scheme. This seems reasonable since the relationship between IWR and P-ET 0 is a simplified representation of a single underlying mechanism, i.e. water consumption by plants, involving many components formulated as a sequence of equations used in all IWR simulations. The few models that do not fit the scheme before bias correction are those simulating P regimes not representative for the study region. Intensity dependent bias correction via QM indeed 
improves the entire distribution of all daily meteorological variables and does not only simply shift their mean from the original grid cell's to the station's conditions, which would not solve problems with the soil water balance related to an overestimation of extremes.

\subsection{Differential climate change impact and uncertainty across stations and crops}

Differences in observed seasonal $\mathrm{P}, \mathrm{ET}_{0}$ and IWR between VIS and AIG as well as differences in the changes and uncertainty to be expected according to bias corrected scenarios were already mentioned along with the description of Fig. 1b, 2, 3 and Table 1. Figure 3 gives an insight into the intra-annual picture (average over 29 years) and introduces results obtained for maize (at AIG), only grown in the lower part of the catchment, together with those for grassland (at VIS), which is the dominant agricultural land use type across the catchment.

Whereas observed monthly P $(50 \mathrm{~mm})$ varies little over the year at VIS (Fig. 3a), it nearly doubles from winter to summer at AIG with a peak in July of about $115 \mathrm{~mm}$ (Fig. 3b). At both stations $\mathrm{ET}_{0}$ peaks in July together with temperature and radiation. At AIG $\mathrm{ET}_{0}$ equals the increasing amount of P from April to July, while it exceeds it during 7 months at VIS, by up to $200 \%$ in July. This generates a large atmospheric water deficit $(-100 \mathrm{~mm}$ in July) at VIS inducing accordingly high IWR. At AIG, although P exceeds $\mathrm{ET}_{0}$ in August-September, IWR is still positive (as seen in Fig. 2e) due to water losses, with $50 \mathrm{~mm}$ being required at the maximum in July. The shorter period of water shortage at AIG is not only due to more humid climate but also to the shorter growing season of maize bounded by sowing and harvest, while grassland covers the ground all year round, causing a difference in water demand in spring and autumn.

Though no change (AIG, $-1 \pm 36 \mathrm{~mm}$, Table 1) or even an increase (VIS, $+22 \pm 18 \mathrm{~mm}$, Table 1) is projected for P integrated over March to October (or April to September for maize, AIG,$-8 \pm 40 \mathrm{~mm}$, Table 1), a decrease in July-August is consistent across scenarios for both situations (down to an average of $-20 \mathrm{~mm}$ at $\mathrm{AIG}$, about $-20 \%$ of the Obs value), as shown by the confidence interval being almost entirely below zero (Fig. $3 \mathrm{c} \& \mathrm{~d}$ ). The seasonally integrated (Fig. 1b and Table 1) less dramatic future change signal (of unknown or opposite sign for AIG and VIS, respectively) than on a monthly basis is due to the large uncertainty and intra-annual variability.

Given the smaller uncertainty around $\mathrm{ET}_{0}$ change, we are confident in the all-year-round trend toward an increase peaking in July at both stations (up to a median of $+10 \mathrm{~mm}$ at VIS, about $+7 \%$ of the Obs value) (Fig. 3 e \& f). Hence, for both situations the projected increase in atmospheric water deficit, driven by the Change in $\mathrm{ET}_{0}$ at VIS and by the Change in $\mathrm{P}$ at AIG, leads to increased IWR by more than $+10 \mathrm{~mm}$ in July (that is by $+15 \%$ for grassland at VIS and $+30 \%$ for maize at AIG, relative to the Obs amounts) (Fig. $3 \mathrm{~g} \& \mathrm{~h}$ ). The most extreme scenario (HC_HadRM3Q16_HadCM3Q16) predicts an increase exceeding $+30 \mathrm{~mm}$ in July at both stations while the least extreme (METNO_HIRHAM_BCM) predicts nearly no Change in IWR, illustrating the large uncertainty in magnitude in spite of the robust positive sign. This large spread in the projections of future IWR challenges decision making; while the need for adaptive measures is given by the consistent sign of Change, the extent of the local measures to be taken, such as investments in new irrigation infrastructure or switching to less-demanding cultivars or land use types, depends on the absolute magnitude of Change, which remains uncertain. Thus, decision making should weigh potential crop losses against costs of investments, and consider both negative and positive side-effects and externalities of measures (Hallegatte 2009).

Simulated IWR Change values for grassland at AIG are larger than for maize because of their integration over a longer growing season (Table 1). However, as mentioned above, IWR 

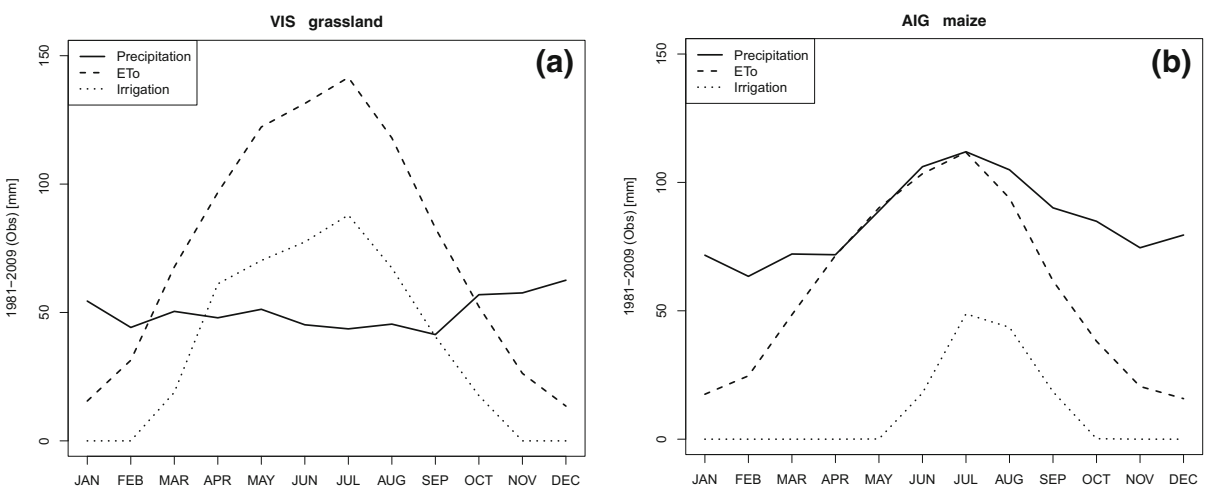

VIS $2021-2049$ vs. $1981-2009$
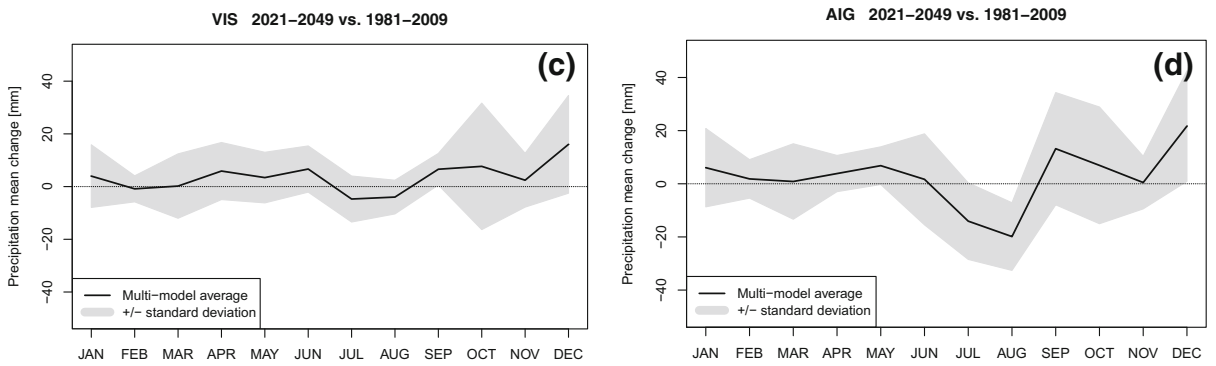

c)

VIS $2021-2049$ vs. $1981-2009$
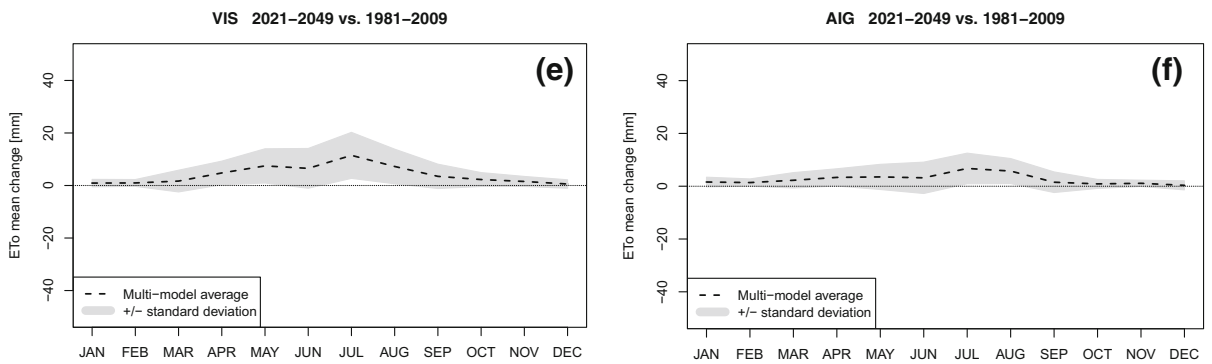

(f)

VIS grassland 2021-2049 vs. 1981-2009

AIG maize $2021-2049$ vs. $1981-2009$
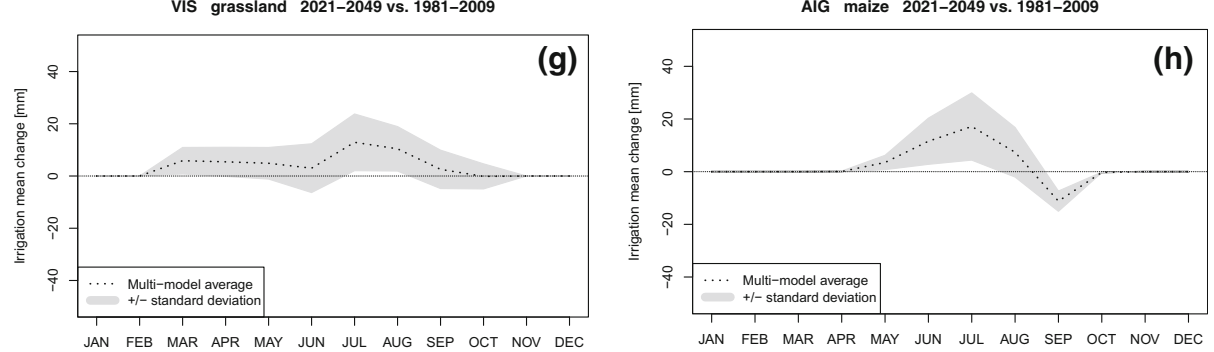

Fig. 3 Time series: 29-year mean observed seasonal cycle of climate (P \& ET $)$ and IWR [mm] for grassland in VIS $\mathbf{a}$ and maize in AIG b. 29-year mean Change signal average and uncertainty (confidence interval + / -standard deviation) across scenarios for $\mathrm{P} \mathbf{c} \& \mathbf{d}, \mathrm{ET}_{0} \mathbf{e} \& \mathbf{f}$ and IWR $\mathbf{g} \& \mathbf{h}[\mathrm{mm}]$

of maize can be larger at a monthly scale (not shown). The peak increase in IWR in July for maize is partly compensated for by an apparent decrease in September due to a shorter cycle in a warmer climate. As discussed in Fuhrer et al. (2013), harvest would occur approximately 
1 month earlier as the thermal requirements to reach maturity would be fulfilled more quickly. The shift in the beginning of the season, as shown by the slight increase in IWR in May (Fig. 3h), also contributes to the earlier harvest. The simulations assumed no change in crop cultivar to adapt to higher temperatures. Such a measure would affect both the seasonal pattern of and the absolute Change in IWR depending on the new crop cultivar's water-use efficiency. In the case of grassland, a warmer climate would extend the growing season length and enable an increased number of cuts or a longer grazing period.

And finally, for irrigation planning, more detailed information based on spatially explicit IWR simulations would be needed that also account for the efficiency of irrigation systems. Such spatial information for shifts in IWR together with estimates of changes in water availability from glacier and snow melt would be essential for designing an effective climate change adaptation strategy. The related study by Fuhrer et al. (2013) using the same bias corrected climate inputs provides a more extended assessment of implications of climate change for agriculture using a selection of scenarios and stations.

\section{Conclusions}

The expected changes (2021-2049 vs. 1981-2009) and associated uncertainty range in the daily precipitation and variables entering the Penman-Monteith reference evapo-transpiration $\left(\mathrm{ET}_{0}\right)$ equation were analyzed. We quantified the impact of these changes on the projected IWR of grassland and maize through simulations of the station, soil, and crop specific daily vertical water balance using the spread of climate scenarios. Particular attention was paid in the process to the effect of the bias correction of the scenarios on the plausibility of simulated climate and impact model outputs.

An increased evaporative demand over the growing season is projected for nearly all stations and scenarios $\left(\mathrm{ET}_{0},-28\right.$ to $\left.+132 \mathrm{~mm}\right)$. The projections are less consistent for $\mathrm{P}$, with either a decrease or increase depending on the scenario, station and month (e.g., average $-20 \%$ in July-August at one of the most humid stations, robust across scenarios). The seasonal cycle of the change signal in IWR shows different sensitivities and drivers across crops and stations, but in all cases a clear trend towards an increase despite uncertainty (e.g. from 0 to over $+30 \mathrm{~mm}$ more water needed in July).

It is demonstrated that bias correction of climate scenarios not only reduces the remaining error between baseline and observations, but also enhances the change signal in seasonal IWR estimates. This is due to a higher and more realistic sensitivity to the atmospheric water budget, the slope of this relationship being steeper in the value range of the observed and corrected baseline points than in that of the uncorrected data points. Even if meteorological variables are corrected separately, they can be successfully used as joint input for an impact model and clearly improve the quality of its outputs. This is remarkable, since it is frequently questioned, whether bias correction methods such as QM degrade inter-variable relationships in a way, that the joint application of bias corrected variables is not advisable. Our results clearly demonstrate the success of bias correction for the chosen application.

We conclude that uncertainty around seasonal projected changes in IWR for stations in the Swiss Rhone catchment is much reduced thanks to bias correction of regional climate scenarios and actually smaller than inter-annual variability over the observed period 19812009: the average signal (10 to $20 \%$ more irrigation water needed) is larger and the spread across scenarios is smaller, the former exceeding the latter after application of the presented method. This means that bias corrected climate data of better quality can be used with more confidence in further similar impact studies. 
Acknowledgments This work was supported by the EU-FP7 Project ACQWA (Assessing Climate impacts on the Quantity and quality of WAter, agreement number 212,250). We thank the Swiss Federal Office of Meteorology and Climatology (MeteoSwiss) and the EU-FP6 Project ENSEMBLES project (contract number 505,539) for granting access to their databases. Thomas Mendlik (Wegener Center, University of Graz) is gratefully acknowledged for helping with scenario data processing.

\section{References}

Allen RG, Pereira LS, Raes D, Smith M (1998) Crop Evapotranspiration: Guidelines for Computing Crop Water Requirements; FAO Irrigation and Drainage Paper 56; Food and Agriculture Organization of the United Nations (FAO). Rome, Italy

Beniston M, Stoffel M, Hill M (2011) Impacts of climatic change on water and natural hazards in the Alps: can current water governance cope with future challenges? Examples from the European "ACQWA" project. Environ Sci Policy 14:734 43

Boberg F, Berg P, Thejll P, Gutowski WJ, Christensen JH (2010) Improved confidence in climate change projections of precipitation further evaluated using daily statistics from ENSEMBLES models. Clim Dyn 35(7-8):1509-1520. doi:10.1007/s00382-009-0683-8

Calanca P, Roesch A, Jasper K, Wild M (2006) Global warming and the summertime evapotranspiration regime of the Alpine region. Clim Chang 79:65-78. doi:10.1007/s10584-006-9103-9

Denis B, Côté J, Laprise R (2002) Spectral Decomposition of two-dimensional atmospheric fields on limited-area domains using the Discrete Cosine Transform (DCT). Mon Weather Rev 130:1812-1829. doi:10.1175/ 1520-0493(2002)130<1812:SDOTDA >2.0.CO;2

Dobler A, Ahrens B (2008) Precipitation by a regional climate model and bias correction in Europe and South Asia. Meteorol Z 17:499-509. doi:10.1127/0941-2948/2008/0306

Deque M (2007) Frequency of precipitation and temperature extremes over France in an anthropogenic scenario: Model results and statistical correction according to observed values, Global Planet. Change 57(1-2):16-26. doi:10.1016/j.gloplacha.2006.11.030

Dosio A, Paruolo P, Rojas R (2012) Bias correction of the ENSEMBLES high resolution climate change projections for use by impact models: Analysis of the climate change signal. J Geophys Res-Atmos 117, D17110. doi:10.1029/2012JD017968

Ehret U, Zehe E, Wulfmeyer V, Warrach-Sagi K, Liebert J (2012) HESS Opinions: Should we apply bias correction to global and regional climate model data? Hydrol Earth Syst Sci 16: 3391-3404

Finger D, Heinrich G, Gobiet A, Bauder A (2012) Projections of future water resources and their uncertainty in a glacierized catchment in the Swiss Alps and the subsequent effects on hydropower production during the 21st century. Water Resources Research 48. doi: 10.1029/2011WR010733

Frei C, Christensen JH, Déqué M, Jacob D, Jones RG, Vidale PL (2003) Daily precipitation statistics in regional climate models: Evaluation and intercomparison for the European Alps. Journal of Geophysical Research 108, no. D3, ACL9-1-19

Fowler HJ, Blenkinsop S, Tebaldi C (2007) Linking climate change modelling to impacts studies: recent advances in downscaling techniques for hydrological modelling. Int J Climatol 27(12):1547-1578. doi:10. $1002 /$ joc. 1556

Fuhrer J (2012) Bewässerungsbedarf und Wasserdargebot unter heutigen und künftigen Klimabedingungen. Zürich, Forschungsanstalt Agroscope Reckenholz-Tänikon ART, http://www.agroscope.admin.ch/ publikationen/05362/index.html?lang = de, $48 \mathrm{pp}$ (in German)

Fuhrer J, Smith PC and Gobiet A (2013) Implications of climate change scenarios for agriculture in alpine regions - A case study in the Swiss Rhone catchment. Science of The Total Environment, Available online 5 July 2013, ISSN 0048-9697, http://dx.doi.org/10.1016/j.scitotenv.2013.06.038 (http://www.sciencedirect. com/science/article/pii/S0048969713006906)

Gobiet A, Kotlarski S, Beniston M, Heinrich G, Rajczak J and Stoffel M (2013) 21st century climate change in the European Alps-A review, Science of The Total Environment, Available online 15 August 2013, ISSN 0048-9697, http://dx.doi.org/10.1016/j.scitotenv.2013.07.050 (http://www.sciencedirect.com/science/article/ pii/S0048969713008188)

Gudmundsson L, Bremnes JB, Haugen JE, Engen-Skaugen T (2012) Technical Note: Downscaling RCM precipitation to the station scale using statistical transformations - a comparison of methods. Hydrol Earth Syst Sci 16(9):3383-3390. doi:10.5194/hess-16-3383-2012

Haerter JO, Hageman S, Moseley C, Piani C (2011) Climate model bias correction and the role of timescales. Hydrol Earth Syst Sci 15:1065-1079 
Hagemann S, Machenhauer B, Jones R, Christensen OB, Déqué M, Jacob D, Vidale PL (2004) Evaluation of water and energy budgets in regional climate models applied over Europe. Clim Dyn 23:547-567. doi:10. 1007/s00382-004-0444-7

Hallegatte S (2009) Strategies to adapt to an uncertain climate change. Glob Environ Chang 19:240-247

Heinrich G, Gobiet A (2012) The future of dry and wet spells in Europe: a comprehensive study based on the ENSEMBLES regional climate models. Int J Climatol 32:1951-1970. doi:10.1002/joc.2421

Heinrich G, Gobiet A, Mendlik T (2013) Extended regional climate model projections for Europe until the mid21st century: combining ENSEMBLES and CMIP3. Clim Dyn. doi:10.1007/s00382-013-1840-7

IPCC (2007) The physical science basis. Contribution of Working Group I to the Fourth Assessment Report of the Intergovernmental Panel on Climate Change. Cambridge University Press, Cambridge, UK, and New York, NY, USA

IPCC (2012) Managing the Risks of Extreme Events and Disasters to Advance Climate Change Adaptation. A Special Report of Working Groups I and II of the Intergovernmental Panel on Climate Change [Field, C.B., V. Barros, T.F. Stocker, D. Qin, D.J. Dokken, K.L. Ebi, M.D. Mastrandrea, K.J. Mach, G.-K. Plattner, S.K. Allen, M. Tignor, and P.M. Midgley (eds.)]. Cambridge University Press, Cambridge, UK, and New York, NY, USA, $582 \mathrm{pp}$

Jacob D, Petersen J, Eggert B, Alias A, Christensen OB, Bouwer L, Braun A, Colette A, Déqué M, Georgievski G, Georgopoulou E, Gobiet A, Menut L, Nikulin G, Haensler A, Hempelmann N, Jones C, Keuler K, Kovats S, Kröner N, Kotlarski S, Kriegsmann A, Martin E, Meijgaard E, Moseley C, Pfeifer S, Preuschmann S, Radermacher C, Radtke K, Rechid D, Rounsevell M, Samuelsson P, Somot S, Soussana JF, Teichmann C, Valentini R, Vautard R, Weber B, and Yiou P (2013) EURO-CORDEX: new high-resolution climate change projections for European impact research, Regional Environmental Change, 1-16, doi:10.1007/s10113-0130499-2

Maraun D (2013) Bias Correction, Quantile Mapping, and Downscaling: Revisiting the Inflation Issue. J Clim 26(6):2137-2143. doi:10.1175/JCLI-D-12-00821.1

Meehl GA, Covey C, Taylor KE et al (2007) The WCRP CMIP3 Multimodel Dataset: A New Era in Climate Change Research. Bull Am Meteorol Soc 88:1383-1394. doi:10.1175/BAMS-88-9-1383

Nakicenovic N, Alcamo J, Davis G, et al. (2000) Special Report on Emissions Scenarios: A Special Report of Working Group III of the Intergovernmental Panel on Climate Change. Cambridge University Press, Cambridge, UK, and New York, NY, USA

Piani C, Haerter JO, Coppola E (2010) Statistical bias correction for daily precipitation in regional climate models over Europe. Theor Appl Climatol 99:187-192. doi:10.1007/s00704-009-0134-9

Prein AF, Gobiet A, Truhetz H (2011) Analysis of uncertainty in large scale climate change projections over Europe. Meteorol Z 20:383-395. doi:10.1127/0941-2948/2011/0286

Smith PC, Calanca P, Fuhrer J (2012) A simple scheme for modelling irrigation water requirements at the regional scale applied to an Alpine river catchment. Water 4:869-886

Steininger KW, Weck-Hannemann H (eds) (2002) Global Environmental Change in Alpine Regions. Recognition, Impact, Adaptation and Mitigation. Edward Elgar, Cheltenham

Suklitsch M, Gobiet A, Leuprecht A, Frei C (2008) High resolution sensitivity studies with the regional climate model CCLM in the Alpine region. Meterol Z 17(4):467-476. doi:10.1127/0941-2948/2008/0308

Suklitsch M, Gobiet A, Truhetz H, Awan NK, Göttel H, Jacob D (2011) Error characteristics of high resolution regional climate models over the Alpine area. Clim Dyn 37(1):377-390. doi:10.1007/s00382-010-0848-5

Taylor KE, Stouffer RJ, Meehl GA (2012) An Overview of Cmip5 and the Experiment Design. Bull Am Meteorol Soc 93(4):485-498. doi:10.1175/BAMS-D-11-00094.1

Themessl MJ, Gobiet A, Heinrich G (2011a) Empirical-statistical downscaling and error correction of regional climate models and its impact on the climate change signal. Clim Chang 112:449-468. doi:10.1007/s10584011-0224-4

Themessl MJ, Gobiet A, Leuprecht A (2011b) Empirical-statistical downscaling and error correction of daily precipitation from regional climate models. Int J Climatol 31:1530-1544. doi:10.1002/joc.2168

van Vuuren DP, Edmonds J, Kainuma M, Riahi K, Thomson A, Hibbard K, Hurtt GC, Kram T, Krey V, Lamarque J, Masui T, Meinshausen M, Nakicenovic N, Smith SJ, Rose SK (2011) The representative concentration pathways: an overview, Clim. Change 109(1-2):5-31. doi:10.1007/s10584-011-0148-Z

Viviroli D, Weingartner R (2008) Water towers - A global view on the hydrological importance of mountains. In: Wiegandt E, editor. Mountains: Sources of Water, Sources of Knowledge. Adv Global Chang Res 31:15-20, Dordrecht; Springer-Verlag

Wilcke R, Mendlik T, and Gobiet A (2013) Performance and Consistency of Multi-Variable Downscaling and Error-Correction of Regional Climate Models, Clim. Change, doi:10.1007/s10584-013-0845-x

Yang W, Andréasson J, Graham LP, Olsson J, Rosberg J, Wetterhall F (2010) Distribution-based scaling to improve usability of regional climate model projections for hydrological climate change impact studies. Hydrol Res 41(3/4):211-229 